\title{
Surfactant Mediated Synthesis of Polyhydroxybutyrate (PHB) Nanoparticles for Sustained Drug Delivery ${ }^{\dagger}$
}

\author{
Sree Samanvitha Padmanaban ${ }^{1, *}$, Dawn S.S. ${ }^{2}$, Senthilkumar P. ${ }^{3}$ \\ 1 Department of Industrial Biotechnology, SASTRA University, Tanjore \\ 2 Center for Waste Management, Sathyabama Institute of Science and Technology, Chennai - 600119, India \\ 3 Department of Chemical Engineering, School of Bio and Chemical Engineering, Sathyabama Institute of Science and \\ Technology, Chennai 600119, Tamil Nadu, India \\ * Correspondence: sreesamanvitha95@gmail.com; \\ $\dagger$ Presented at International e-Conference on Bioengineering for Health and Environment (ICBHE 2020)
}

Received: 5.07.2020; Revised: 10.07.2020; Accepted: 12.07.2020; Published: 15.07.2020

\begin{abstract}
Polyhydroxyalkanoates are produced by bacterial fermentation that contains ester as their functional group. Polymeric substances derived from living organisms are captivating owing to the fact of their adaptability, biocompatibility, and biodegradability. The main objective of this study is to develop polymeric nanoparticles through the nanoprecipitation method using the PHA extracted from Pseudomonas aeruginosa. In this study, PHA extracted was characterized and determined as Polyhydroxybutyrate. The PHA was further used to produce nanoparticles by nanoprecipitation method using Dichloromethane as a solvent and subjected to various characterizations such as UltravioletVisible spectroscopy (UV-Vis), Fourier Infra-Red spectroscopy (FTIR), Field Emission Scanning Electron microscopy (FeSEM) and further tested for sustained drug release. Nanoparticles prepared by the nanoprecipitation method had a size with invariable dissemination. Curcumin loaded PHA nanoparticles displayed a competent antibacterial effect against Bacillus subtilis. A controlled drug release was exhibited.
\end{abstract}

Keywords: PHA; Polyhydroxybutyrate; Bacillus subtilis.

(C) 2020 by the authors. This article is an open-access article distributed under the terms and conditions of the Creative Commons Attribution (CC BY) license (https://creativecommons.org/licenses/by/4.0/).

\section{Funding}

This research received no external funding.

\section{Acknowledgments}

This research has no acknowledgment.

\section{Conflicts of Interest}

The authors declare no conflict of interest. 